\title{
Imaging Spectrum of Pediatric Nonspecific Aortoarteritis on CT Angiography: A Retrospective Study
}

\author{
Ashish Verma ${ }^{1}$ Ishan Kumar ${ }^{1}$ Priyanka Aggarwal ${ }^{2}$ \\ ${ }^{1}$ Department of Radiodiagnosis and Imaging, Institute of Medical \\ Sciences, Banaras Hindu University, Varanasi, India \\ 2Department of Paediatrics, Institute of Medical Sciences, Banaras \\ Hindu University, Varanasi, India
}

\author{
Ram C. Shukla ${ }^{1}$
}

\begin{abstract}
Address for correspondence Ishan Kumar, MBBS, MD, DNB, Department of Radiodiagnosis and Imaging, Institute of Medical Sciences, Banaras Hindu University, Varanasi 221005, India (e-mail: ishanjd@gmail.com).
\end{abstract}

\begin{abstract}
Keywords

- Takayasu's arteritis

- pediatric

- nonspecific aortoarteritis

- CT angiography

Introduction Takayasu's arteritis, a chronic, idiopathic, inflammatory panarteritis, is the major cause of Aortoarteritis in pediatric age group. The purpose of this study is to analyze the patterns of involvement and imaging findings of pediatric Takayasu's arteritis.

Materials and Methods We retrospectively reviewed the CT angiographic images of 11 pediatric cases reported as "Takayasu's arteritis" or "nonspecific arteritis" over the period of last 3 years.

Results Mural thickening with luminal stenosis was the most common findings. Aneurysmal dilatation of the descending thoracic aorta was observed in one case. Vessel stenoses without mural thickening, thrombosis and collateral vessel formation were the other findings. Pattern of involvement ranged from variable involvement of thoracic and abdominal aorta and their branches.

Conclusion Awareness of its CT angiographic appearances and distribution pattern can help the clinicians and radiologists to have high index of suspicion in aiding early diagnosis and better management of this disease
\end{abstract}

\section{Introduction}

Aortoarteritis, is a blanket term that accommodates a wide array of infectious and noninfectious inflammatory conditions which involve aorta and its major branches. The multitude and nonspecific nature of its clinical symptoms often lead to delayed diagnosis and thereby compromised management of these patients. Large vessel vasculitides such as Takayasu disease and giant cell arteritis are the major noninfectious causes; however, other collagen vascular diseases such as rheumatoid arthritis and ankylosing spondylitis also can lead to aortoarteritis. Infectious aortitis was usually a complication of infectious endocarditis in preantibiotic era. Aorta is normally very resistant to infection and infectious aortitis is nowadays usually associated with pre-existing aortic aneurism, diabetes, cystic medial necrosis, or surgery. Staphylococcus aureus, salmonella species, and tuberculosis are the usual culprits. ${ }^{1}$ Takayasu's arteritis, a chronic, idiopathic, inflammatory panarteritis, is the major cause of aortoarteritis in pediatric age group. In children, it is the most common cause of renovascular hypertension. ${ }^{2}$ The disease is common in India which befits its proposed causal association with tuberculosis. The nature of this association is however not completely understood yet. In 1994 the Takayasu Conference in Tokyo proposed an angiographic classification, which divides the disease in six subgroups ( - Table 1). In addition, an appendage of a " $\mathrm{C}+$ " or "P+" was used to denote coronary or pulmonary involvement. ${ }^{3,4}$

Ultrasound with Color Doppler is the first diagnostic modality used for screening of the disease which can assess branches of aortic arch, abdominal aorta, and its branches and can show downstream flow changes in the extremities. Conventional angiography has been traditionally considered gold standard for diagnosis. ${ }^{5}$ However, they have been largely replaced by noninvasive modalities such as $\mathrm{CT}$ angiography 
Table 1 Angiographic classification of Takayasu's arteritis

\begin{tabular}{|l|l|}
\hline Type I & Branches from the aortic arch \\
\hline Type Ila & $\begin{array}{l}\text { Ascending aorta, aortic arch, and } \\
\text { its branches }\end{array}$ \\
\hline Type IIb & $\begin{array}{l}\text { Ascending aorta, aortic arch, and } \\
\text { its branches, thoracic descending } \\
\text { aorta }\end{array}$ \\
\hline Type III & $\begin{array}{l}\text { Thoracic descending aorta, } \\
\text { abdominal aorta, and/or renal } \\
\text { arteries }\end{array}$ \\
\hline Type IV & $\begin{array}{l}\text { Abdominal aorta and/or renal } \\
\text { arteries }\end{array}$ \\
\hline Type V & $\begin{array}{l}\text { Combined features of Types IIb } \\
\text { and IV }\end{array}$ \\
\hline
\end{tabular}

and MRI which can demonstrate mural changes even before luminal narrowing occur.

\section{Materials and Methods}

We searched our CT scan center archives to look for the word "Takayasu's arteritis" or "nonspecific arteritis" reported over the period of last 3 years. From the total cases, we selected patients with age less than 18 years. The diagnosis of Takayasu's arteritis was based on criteria given by Sharma et al according to which presence of two major, or one major and two minor, or four minor criteria suggested the diagnosis (- Table 2). ${ }^{6} \mathrm{CT}$ angiography was performed on all the cases by 64-channel multidetector CT (Lightspeed Ultra, GE Medical Systems, Milwaukee, WI). A 20-gauge needle was placed into the antecubital vein, and nonionic contrast material, iohexol (Omnipaque 300; GE Healthcare) was injected at a rate of 2.5 to $3.0 \mathrm{~mL} / \mathrm{s}$ using a power injector (OptiVantage DH; Tyco, Mallinckrodt) in amount of 2 $\mathrm{mL} / \mathrm{kg}$. Slice thickness of $1.25 \mathrm{~mm}$ was used during arterial and venous phase with pitch value of 1 .

\section{Results}

A total of 23 patients were reported as Takayasu's arteritis or nonspecific aortoarteritis. Of these 23 patients 11 were

Table 2 Diagnostic criteria for Takayasu's arteritis

\begin{tabular}{|c|c|}
\hline Major criteria & Minor criteria \\
\hline $\begin{array}{l}\text { - Left mid-subclavian } \\
\text { artery lesion } \\
\text { - Right mid-subclavian } \\
\text { artery lesion } \\
\text { - Characteristic signs } \\
\text { and symptoms of at } \\
\text { least 1-month duration } \\
\text { (including limb claudi- } \\
\text { cation, pulselessness } \\
\text { or pulse differences in } \\
\text { limbs, an unobtainable } \\
\text { or significant blood } \\
\text { presence difference, } \\
\text { fever, neck pain, tran- } \\
\text { sient amaurosis, blurred } \\
\text { vision, syncope, dyspnea, } \\
\text { or palpitations) }\end{array}$ & $\begin{array}{l}\text { - High erythrocyte sedi- } \\
\text { mentation rate } \\
\text { - Carotid artery tenderness } \\
\text { Hypertension } \\
\text { - Aortic regurgitation or } \\
\text { annuloaortic ectasia } \\
\text { - Pulmonary artery lesion } \\
\text { - Left mid-common carotid } \\
\text { lesion } \\
\text { - Distal brachiocephalic } \\
\text { trunk lesion } \\
\text { - Descending thoracic aorta } \\
\text { lesion } \\
\text { - Abdominal aorta lesion } \\
\text { - Coronary artery lesions }\end{array}$ \\
\hline
\end{tabular}

of pediatric age group ( $<18$ years) and we retrospectively reviewed CT angiographic findings of these 11 pediatric patients of Takayasu's disease. Three of them were males and 8 were females. Their age ranged from 12 to 18 years (mean age 15 years). In 5 out of 11 patients, both abdominal and thoracic aorta with their branches were involved. Isolated thoracic and isolated abdominal aorta with their branches were involved in three cases each. Pattern of distribution of disease is summarized in - Table 3. Two of the patients showed pulmonary artery dilatation and coronary arteries were involved in none of the cases. Ten out of 11 patients were started on prednisone. One was given prednisone with antitubercular regimen as CT raised suspicion of tuberculosis revealing mediastinal and retroperitoneal lymphadenopathy and cavitary lesions in lungs along with bronchiectasis which was confirmed on histopathological examination. Antihypertensive drugs were given in the patients presenting with hypertension. No follow-up CT scan was performed predominantly due to financial issues and patients were followed up mainly by clinical examination, erythrocyte sedimentation rate levels, and Doppler studies wherever possible.

Typical CT angiographic features of the patients are summarized in - Table $\mathbf{4}$ and - Table $\mathbf{5}$ in thoracic and abdominal lesions. Mural thickening with luminal stenosis was the most common finding (-Figs. 1 and 2). Aneurysmal dilatation of the descending thoracic aorta was observed in one case (-Fig. 2). Vessel stenosis without mural thickening, thrombosis and dilatation were the other findings. Collateral vessels were observed in many cases both in thoracic and abdominal vessels (-Fig. 3). In thorax these vessels were visible around subclavian and carotid arteries predominantly derived from intercostal vessels. In abdomen multiple retroperitoneal, and abdominal wall collateral vessels were

Table 3 Pattern of involvement in 11 pediatric cases of Takayasu's disease

\begin{tabular}{|l|l|l|}
\hline Involved segment & No. of cases & $\%$ \\
\hline Ascending aorta & 2 & 18.2 \\
\hline Arch of aorta & 3 & 27.3 \\
\hline Descending aorta & 7 & 63.6 \\
\hline $\begin{array}{l}\text { Proximal abdominal } \\
\text { aorta }\end{array}$ & 4 & 36.4 \\
\hline Mid abdominal aorta & 4 & 36.4 \\
\hline Distal abdominal aorta & 3 & 27.3 \\
\hline $\begin{array}{l}\text { Right common carotid } \\
\text { artery }\end{array}$ & 2 & 18.2 \\
\hline $\begin{array}{l}\text { Left common carotid } \\
\text { artery }\end{array}$ & 4 & 36.4 \\
\hline Brachiocephalic artery & 2 & 18.2 \\
\hline Right subclavian artery & 2 & 18.2 \\
\hline Left subclavian artery & 6 & 54.6 \\
\hline $\begin{array}{l}\text { Superior mesenteric and/ } \\
\text { or celiac artery }\end{array}$ & 3 & 27.3 \\
\hline Right renal artery & 4 & 36.4 \\
\hline Left renal artery & 7 & 63.6 \\
\hline
\end{tabular}


Table 4 Sites of involvement and findings on CT angiography in eight pediatric patients of Takayasu's arteritis with thoracic lesions

\begin{tabular}{|l|l|l|l|l|l|l|l|l|l|l|l|}
\hline \multirow{2}{*}{ Artery involved } & \multicolumn{2}{l}{ Mural thickening } & \multicolumn{2}{l|}{ Dilatation } & \multicolumn{2}{l|}{ Thrombi } & \multicolumn{2}{l|}{ Ulcer like lesion } & \multicolumn{2}{l|}{ Collateralization } \\
\cline { 2 - 16 } & No. & $\%$ & No. & $\%$ & No. & $\%$ & No. & $\%$ & No. & $\%$ \\
\hline Ascending thoracic aorta & 2 & 25 & 0 & 0 & 0 & 0 & 0 & 0 & 1 & 12.5 \\
\hline Arch of aorta & 3 & 37.5 & 0 & 0 & 0 & 0 & 0 & 0 & 1 & 12.5 \\
\hline Descending thoracic aorta & 7 & 87.5 & 1 & 12.5 & 1 & 12.5 & 1 & 12.5 & 0 & 0 \\
\hline Brachiocephalic & 2 & 25 & 0 & 0 & 0 & 0 & 0 & 0 & 0 & 0 \\
\hline Common carotid (right) & 2 & 25 & 0 & 0 & 0 & 0 & 0 & 0 & 1 & 12.5 \\
\hline Common carotid (left) & 4 & 50 & 0 & 0 & 1 & 12.5 & 0 & 0 & 3 & 37.5 \\
\hline Subclavian (right) & 2 & 25 & 0 & 0 & 0 & 0 & 0 & 0 & 2 & 25 \\
\hline Subclavian (left) & 5 & 62.5 & 0 & 0 & 1 & 12.5 & 0 & 0 & 6 & 75 \\
\hline Vertebral (right) & 1 & 12.5 & 0 & 0 & 0 & 0 & 0 & 0 & 1 & 12.5 \\
\hline Vertebral (left) & 2 & 25 & 0 & 0 & 0 & 0 & 0 & 0 & 2 & 25 \\
\hline Pulmonary artery & 0 & 0 & 2 & 25 & 0 & 0 & 0 & 0 & 0 & 0 \\
\hline
\end{tabular}

Table 5 Sites of involvement and findings on CT angiography in eight pediatric patients of Takayasu's arteritis with abdominal lesions

\begin{tabular}{|l|l|l|l|l|l|l|l|l|}
\hline \multirow{2}{*}{ Segment involved } & \multicolumn{3}{l}{ Mural thickening } & \multicolumn{3}{l}{ Ostial narrowing } & \multicolumn{2}{l|}{$\begin{array}{l}\text { Stenosis without } \\
\text { thickening }\end{array}$} \\
\cline { 2 - 11 } & No. & $\%$ & No. & $\%$ & No. & $\%$ & No. & $\%$ \\
\hline Proximal abdominal aorta & 4 & 50 & 0 & 0 & 0 & 0 & 1 & 12.5 \\
\hline Mid abdominal aorta & 4 & 50 & 0 & 0 & 0 & 0 & 0 & 0 \\
\hline Distal abdominal aorta & 1 & 12.5 & 0 & 0 & 2 & 25 & 0 & 0 \\
\hline $\begin{array}{l}\text { Celiac trunk and superior } \\
\text { mesenteric artery }\end{array}$ & 0 & 0 & 2 & 25 & 1 & 12.5 & 0 & 0 \\
\hline Right renal artery & 0 & 0 & 4 & 50 & 3 & 37.5 & 0 & 0 \\
\hline Left renal artery & 1 & 12.5 & 7 & 87.5 & 4 & 50 & 2 & 25 \\
\hline
\end{tabular}

observed. Paravertebral and inferior mesenteric artery also contributed to the formation of collateral around renal artery in one case. One of the cases also revealed pontine infarct. In abdomen, involvement of aorta and renal arteries was the most commonly involved site with cases presenting with diffuse mural thickening leading to diffuse narrowing as well as ostial stenosis. Ostial stenosis was also seen at the origin of celiac and superior mesenteric artery ( - Fig. 4). Two cases of vessel lumen thrombosis were seen, one involving left subclavian and other involving right common carotid artery (-Fig. 5). One of the cases of descending thoracic aortic aneurysm was partially thrombosed ( - Fig. 2 ).

\section{Discussion}

Takayasu's disease, also known as Martorell syndrome, occlusive thromboaortopathy, or pulseless disease, has a more aggressive course in pediatric age group with a reported 5-year mortality rate of 35 to $40 \% .^{7-9}$ Many studies have shown it to be associated with tuberculosis; however, the nature of association is not clear. ${ }^{7}$ One out of 11 of our cases also had tuberculosis and was treated with steroid as well as antitubercular regimen. Takayasu's arteritis is difficult to diagnose in children as most of the cases present with generalized systemic manifestations and nonspecific complaints. However, high degree of suspicion is mandated in our country given the disease has relative frequency in this region. The disease has a predilection for young female as also found in our study.

The clinical symptoms correlated well with the pattern of vessel involvement of the disease in our study. Eight out of 11 cases presented with hypertension, seven of which revealed renal artery involvement on CT angiography. One of them was associated with renal infarct. Cases with symptoms like headache, dizziness, neck tenderness revealed carotid and vertebral artery involvement on imaging. One of the cases also revealed pontine infarct. Cases with abdominal aortic involvement are related with vague abdominal pain and other abdominal symptoms. Different investigation modalities have been used to evaluate Takayasu's arteritis. Sonography remains primary modality to evaluate carotid and subclavian arteries and was used in follow up of the patients in our study. CT angiography has largely replaced conventional angiography in diagnosis and work up of these patients because besides luminal changes $\mathrm{CT}$ can also assess mural thickening, intraluminal thrombus, collateral vessels, 


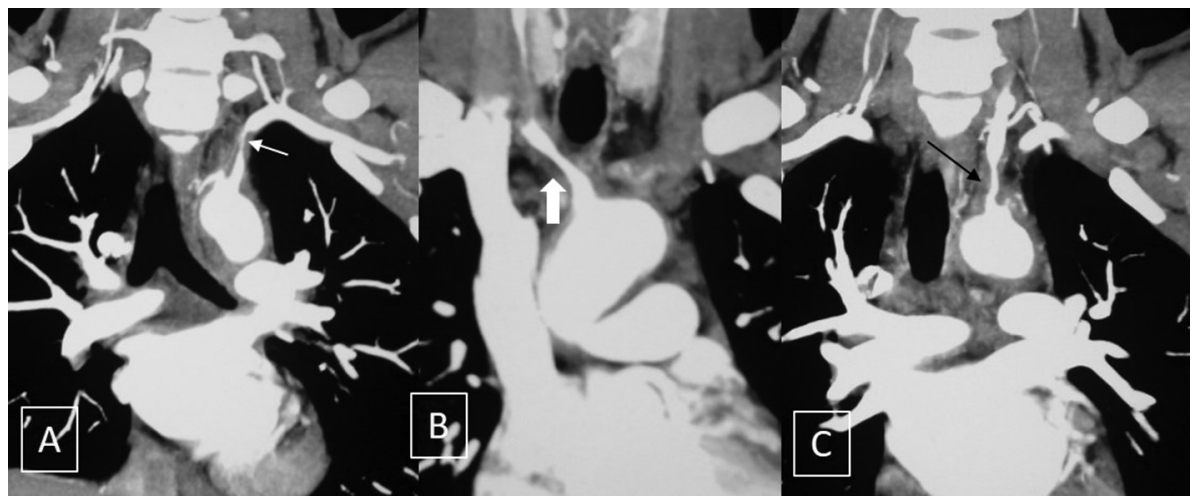

Fig. 1 Short segment mural thickening with luminal narrowing is seen in left subclavian (white arrow in A), brachiocephalic (solid white arrow in B) and left common carotid (black arrow in C) arteries.

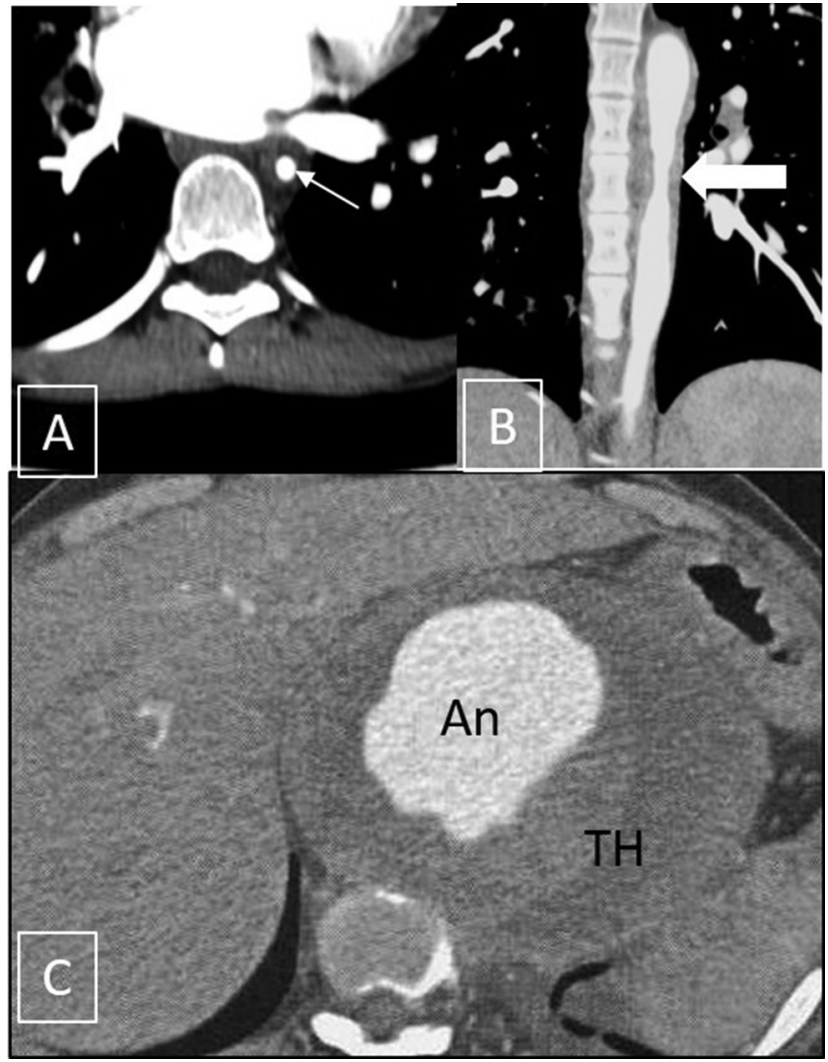

Fig. 2 (A, B) These figures show circumferential mural thickening in descending thoracic aorta causing significant luminal narrowing (white arrows). Another patient (C) showing aneurysmal dilatation of the involved aortic segment (An) with partial luminal thrombosis $(\mathrm{TH})$.

and other end organ changes unlike conventional angiography. ${ }^{10-12}$ In our study we came across following findings on CT angiography.

\section{Vessel Wall Thickening}

Mural thickening, with or without luminal stenosis, and increased vessel wall enhancement of the involved segment are the most common findings that are associated with this disease. Various studies have shown the decrease of mural thickening and enhancement with treatment. ${ }^{10-12}$ Paul et al

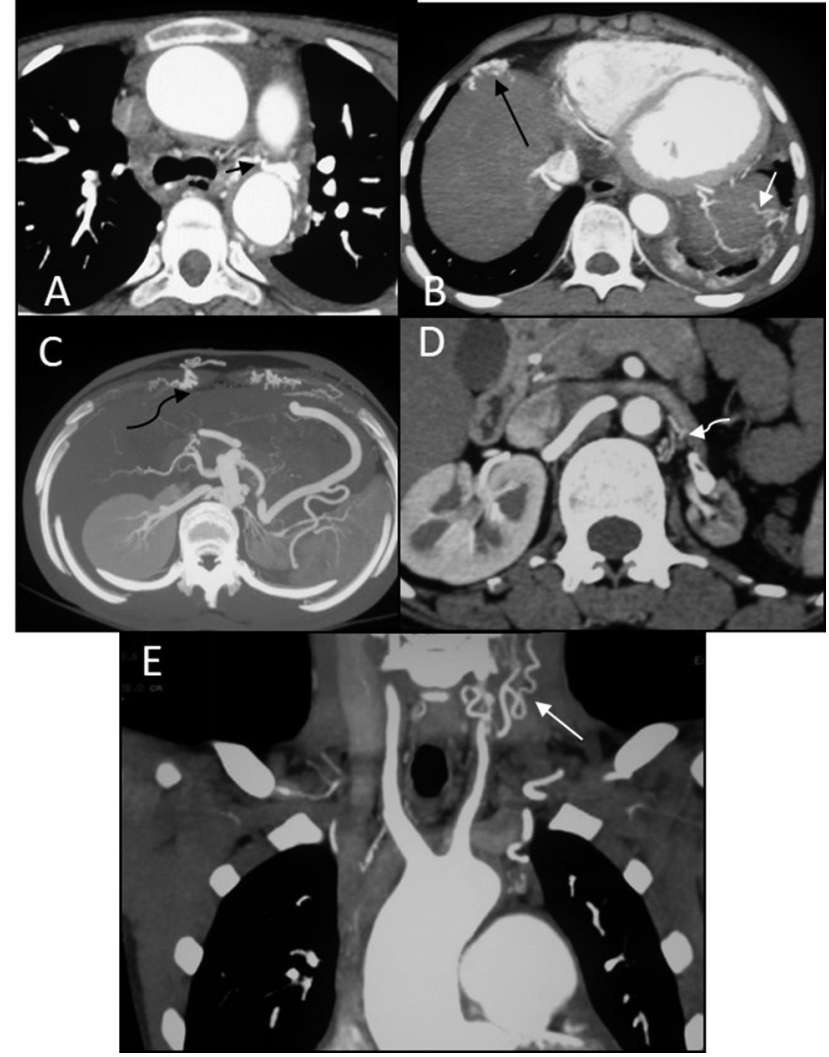

Fig. 3 Multiple collateral vessels are seen in various patients in $C T$ angiographic images: aortopulmonary (A, short black arrow), left phrenic (B, small white arrow), anterior perihepatic (B, large white arrow), anterior abdominal wall (C, curved black arrow), left cervical collaterals (E, large white arrow are seen). (D) This shows paravertebral collaterals replacing left renal artery in a case (curved black arrow).

studied the role of electron beam CT in follow up of 16 patients and demonstrated the decrease of vessel wall thickening with appearance of wall calcification with treatment. ${ }^{5}$ In our study all the cases were associated with enhancing soft tissue density thickening of vessel walls. Transmural calcification of thickened arterial wall is also an important feature of Takayasu's arteritis and is seen in approximately one-third of patients. Few studies have reported double ring pattern enhancement in the thickened vessel wall. ${ }^{13}$ 


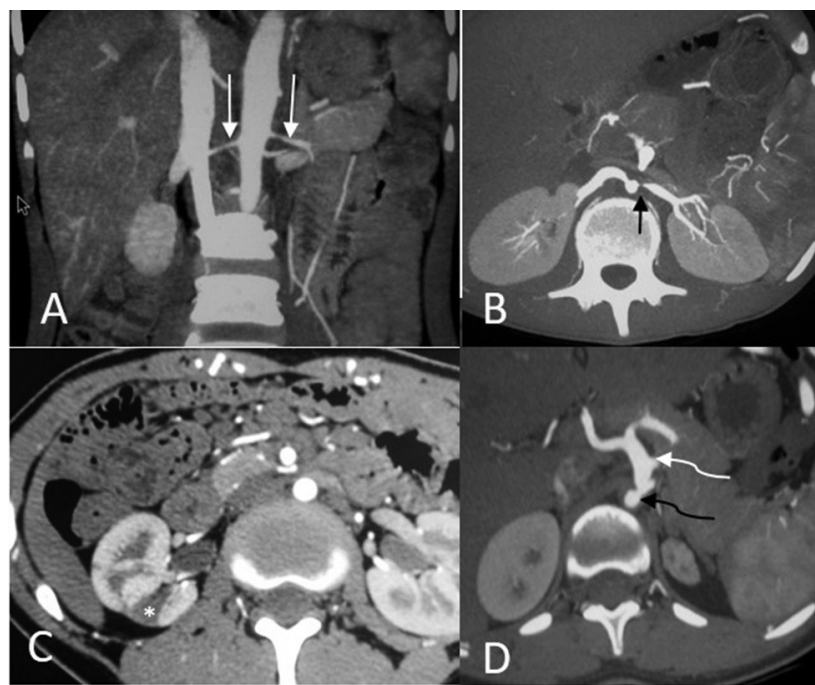

Fig. 4 Diffuse mural thickening and narrowing of bilateral renal artery in a patient (A, white arrows). Another patient shows ostial stenosis of the origin of left renal artery (B, black arrow). Small renal infarct $\left({ }^{*}\right)$ is depicted in (C). A patient with abdominal involvement (D) shows thickening and stenosis of proximal abdominal aorta with ostial stenosis (curved black arrow) of origin of celiac trunk with poststenotic dilatation (curved white arrow).

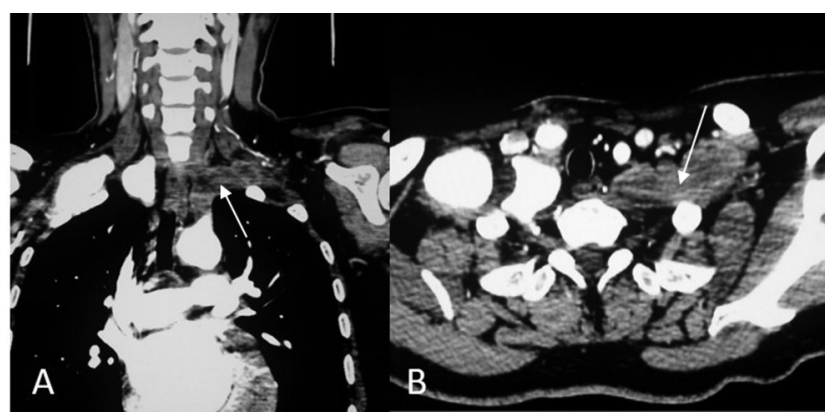

Fig. 5 Coronal (A) and axial (B) images showing complete thrombotic occlusion of left subclavian artery (white arrows).

\section{Segmental Vessel Narrowing and Ostial Stenosis}

Luminal narrowing can be observed in $90 \%$ of the patients. ${ }^{13,14}$ The narrowing can be either due to arterial wall thickening or can be associated with vessel wall inflammation and fibrosis. In our study, segmental stenosis was found most commonly in abdominal aorta, descending thoracic aorta, and branches of aortic arch predominantly in subclavian and carotid arteries. Narrowing at the origin of renal arteries ( 7 out of 11 ), celiac trunk, and superior mesenteric arteries ( 2 out of 11) was also found. Takayasu's arteritis is the most common cause of renal artery stenosis. Carotid and extremity artery stenosis can lead to cerebrovascular stroke or limb claudication. ${ }^{13,14}$ Recently a case of supravalvular aortic stenosis caused by Takayasu's arteritis has been reported. ${ }^{15}$

\section{Intraluminal Thrombus}

Thrombus formation in Takayasu's arteritis can be attributed to raised platelet count and raised plasma levels of platelet factor 4 , beta thromboglobulin, thrombin/antithrombin complex, fibrinopeptide A, and D-dimer as demonstrated by various studies. ${ }^{10,16}$ In our study thrombosis of subclavian, carotid, and renal arteries was observed. A partially thrombosed aneurysm was also seen in descending thoracic aorta. Besides the thrombosis of the involved arterial lumen, various reports have described venous thrombosis due to hypercoagulable states. Isolated case reports have described cases of cerebral venous thrombosis presenting as acute onset headache and superior mesenteric vein thrombosis presenting as acute abdomen in Takayasu's arteritis. ${ }^{17}$ However, due to the rarity of venous thrombosis it has not been established whether thromboembolic event have an association with arteritis or is just anecdotal.

\section{Collateral Vessels}

Where there is blood, there is a way. Chronic luminal occlusion instigates formation of vascular collaterals and their assessment is useful in planning therapy. Various collateral pathways get recruited to supply the ischemic tissues depending upon the stenosed vessel. In our study we came across various intercostal, paravertebral, abdominal and chest wall, retroperitoneal and mesenteric collaterals. A notable collateral pathway that has been described in the obstruction of aorta is Winslow pathway, which connects internal thoracic artery, superior and inferior epigastric artery, and external iliac artery. Prominent Winslow pathway can lead to limb claudication due to stealing effect as well as systemic arterial hypertension. ${ }^{18} \mathrm{An}$ isolated case report has described a coronary-carotid collateral pathway originating from left anterior descending artery and left circumflex arteries. CT angiography can provide an accurate understanding of the anatomy of collaterals in every patient. Depending on the symptomatology, CT angiography also may aid in therapeutic decision of percutaneous embolization of the collateral responsible for the symptom. ${ }^{19}$

\section{Other Miscellaneous Findings}

Additionally CT angiography can also demonstrate aneurismal dilatation of involved vessel, pulmonary and coronary artery involvement. Pulmonary and coronary artery involvement has been reported in 63.3 and $44.4 \%$, respectively. ${ }^{10}$ However, in our study 2 out of 11 (18.2\%) cases involved pulmonary artery and none of the cases revealed coronary artery involvement. CT also helps to evaluate end organ changes such as renal parenchymal atrophy, renal and cerebral infarcts and thus helps in modifying treatment protocol. Rare manifestations of Takayasu's arteritis include brain leptomeningitis, intracranial arteritis, and pyodermagangrenosum. ${ }^{20-22}$

Recently there has been interest in the role of MRI in Takayasu arteritis as it can detect very early mural changes with better sensitivity and can give useful information about disease activity. ${ }^{23}$ [18F]-Fluorodeoxyglucose positron emission tomography has also been proposed to evaluate response to treatment in Takayasu arteritis.

\section{Conclusion}

Takayasu disease follows more hostile course in pediatric age group with high mortality. Awareness of its CT angiographic appearances and distribution pattern can help the 
clinicians and radiologists to have high index of suspicion in aiding early diagnosis and better management of this disease.

\section{Conflict of Interest}

None declared.

\section{References}

1 Restrepo CS, Ocazionez D, Suri R, Vargas D. Aortitis: imaging spectrum of the infectious and inflammatory conditions of the aorta. Radiographics 2011;31(2):435-451

2 Kanitkar M. Renovascular hypertension. Indian Pediatr 2005;42(1):47-54

3 Hata A, Noda M, Moriwaki R, Numano F. Angiographic findings of Takayasu arteritis: new classification. Int J Cardiol 1996;54(Suppl):S155-S163

4 Barto D, Bonta E, Ghiorghe S. Takayasu's arteritis-an update. CercetãriExperimentale\&Medico-Chirurgicale Anul XIII. Nr34/2006:149-152

5 Paul JF, Fiessinger JN, Sapoval M, et al. Follow-up electron beam CT for the management of early phase Takayasu arteritis. J Comput Assist Tomogr 2001;25(6):924-931

6 Sharma BK, Jain S, Suri S, Numano F. Diagnostic criteria for Takayasu arteritis. Int J Cardiol 1996;54(Suppl):S141-S147

7 Morales E, Pineda C, Martínez-Lavín M. Takayasu's arteritis in children. J Rheumatol 1991;18(7):1081-1084

8 Lee KS, Sohn EY, Hong CY, Kang SR, Berg K. Primary arteritis (Pulseless Disease) in Korean children. Acta Paediatr Scand 1967;56(5):526-536

9 Aluquin VPR, Albano SA, Chan F, Sandborg C, Pitlick PT. Magnetic resonance imaging in the diagnosis and follow up of Takayasu's arteritis in children. Ann Rheum Dis 2002;61(6):526-529

10 Akazawa H, Ikeda U, Yamamoto K, Kuroda T, Shimada K. Hypercoagulable state in patients with Takayasu's arteritis. Thromb Haemost 1996;75(5):712-716

11 Kim SY, Park JH, Chung JW, et al. Follow-up CT evaluation of the mural changes in active Takayasu arteritis. Korean J Radiol 2007;8(4):286-294
12 Lupi-Herrera E, Sánchez-Torres G, Marcushamer J, Mispireta J, Horwitz S, Vela JE. Takayasu's arteritis. Clinical study of 107 cases. Am Heart J 1977;93(1):94-103

13 Zhu FP, Luo S, Wang ZJ, Jin ZY, Zhang LJ, Lu GM. Takayasu arteritis: imaging spectrum at multidetector $\mathrm{CT}$ angiography. $\mathrm{Br} \mathrm{J}$ Radiol 2012;85(1020):e1282-e1292

14 Mason JC. Takayasu arteritis-advances in diagnosis and management. Nat Rev Rheumatol 2010;6(7):406-415

15 Kim DY, Kim HW. Atypical initial presentation of Takayasu arteritis as isolated supra-valvular aortic stenosis. J Cardiothorac Surg 2016;11:15

16 Ishikawa K. Natural history and classification of occlusive thromboaortopathy (Takayasu's disease) Circulation 1978;57(1):27-35

17 Huang Y, Ye Z, Zheng Z, et al. Superior mesenteric artery thrombosis of Takayasu arteritis: a case report and review of the literatures. J Am Coll Cardiol 2015;66(16, Supplement):C247

18 Babu SNM, Chacko S, Irodi A, Joseph E, Joseph G. Winslow pathway collaterals in Takayasu arteritis with middle aortic syndrome. IHJ Cardiovasc Case Rep 2019;3:39-43

19 Ando H, Funabashi N, Uehara M, et al. Abnormal collateral arterial systems in Takayasu's arteritis and Leriche's syndrome evaluated by whole body acquisition using multislice computed tomography. Int J Cardiol 2007;121(3):306-308

20 Thokchom NS, Sangma KA, Hafi Bishurul NA, Verma K. Pyoderma Gangrenosum with Takayasu's arteritis: a rare association. J Med Soc 2018;32(3:231-233

21 Tanna D, Mendiratta N, Negalur N. An unusual case of Takayasu arteritis presenting as leptomeningitis with obstructive hydrocephalus. Rheumatol Adv Pract 2018;2(suppl 1):rky033.001

22 Edwards SL, Baker V, Boswell GE, Butts MS. A rare case of Takayasu arteritis with intracranial involvement, aortic valvulitis, and giant cell aortitis. J Clin Rheumatol 2018. Doi: 10.1097/RHU.0000000000000960

23 Choe YH, Han BK, Koh EM, Kim DK, Do YS, Lee WR. Takayasu's arteritis: assessment of disease activity with contrast-enhanced MR imaging. Am J Roentgenol 2000;175(2):505-511 